\title{
Monitoring of temperature gradient development of highway concrete bridge
}

\author{
Lukas Krkoska ${ }^{1, *}$, and Martin Moravcik ${ }^{1}$ \\ ${ }^{1}$ University of Zilina, Faculty of Civil Engineering, Department of Structures and Bridges, \\ Univerzitna 2, 01026 Zilina, Slovakia
}

\begin{abstract}
Thermal effect is one of very important from the large bridge design procedure point of view. Especially vertical temperature gradient is being crucial. There were realized some research works of the thermal effects monitoring on the concrete bridges in the world. More of them were performed in the USA but only a few at European bridges. The short overview of our long-term monitoring of the temperature load on chosen concrete bridge is presented in this paper. We decided to analyse one concrete box girder bridge that was built by incremental launching method on highway D1 at Slovakia near Zilina city. Recorded temperature gradient was compared with thermal gradients for the concrete box girder bridge recommended by EC 1991-1-5 design specifications.
\end{abstract}

\section{Introduction}

Bridges are designed for the 100 years of the service life but they are under traffic even longer. They are exposed to thermal effects daily, seasonal and yearly dependent on the climatic conditions. Thermal effect has been primary characterized as a non-stationary action in time with strong variations caused by solar radiation, ambient air temperature, humidity and wind. The next significant influence that is affecting secondary thermal condition of the bridge being is the bridge dimension itself. Mainly it is structure orientation exposed to the sunshine, material of the deck surface, structure dimensions and cross-section geometry.

Thermal actions have significant effect on bridge structures and can be reason for more than $30 \%$ of the reinforcement used from that point of view. That is why it cannot be neglected in the bridge design process. Thermal actions differ from other load types through being a constraining load. If these deformations are restrained, temperature variations result in thermal stresses, what may lead to stress field changing along the length of structures and cross-section too. A temperature profile can be divided into a constant part which affects the bridge with a linear expansion and a non-uniform part that will induce vertical or horizontal curve shape of the bridge superstructure. Uniform temperature changes cause mostly length changes, expansion or contraction. It is important for the expansion joints but for example it can change the internal forces too of the frame structures. Vertical and horizontal temperature gradient results in additional bending

* Corresponding author: lukas.krkoska@,fstav.uniza.sk 
moments in vertical and horizontal plane, respectively. This makes thermal actions in bridge design interesting for further investigations.

\section{Thermal effects on concrete structures}

The temperature distribution within the concrete bridge deck may be generally split into the four essential constituent components, which are uniform temperature component (effective bridge temperature), $\Delta \mathrm{T}_{\text {unif }}$, linearly temperature difference component about the z-axis, $\Delta \mathrm{T}_{\mathrm{My}}$, and about the $\mathrm{y}$-axis, $\Delta \mathrm{T}_{\mathrm{Mz}}$ and non-linear temperature difference component, $\Delta \mathrm{T}_{\mathrm{E}}$. It results in a system of self-equilibrated stresses.

\begin{tabular}{|c|c|c|c|c|c|c|c|c|c|}
\hline \multirow[b]{2}{*}{ Type of construction } & \multicolumn{9}{|c|}{ Temperature difference $(\Delta \mathrm{T})$} \\
\hline & \multicolumn{4}{|c|}{ (a) Heating } & \multicolumn{5}{|c|}{ (b) Cooling } \\
\hline 3a. Concrete slab & \multirow{2}{*}{\multicolumn{4}{|c|}{$\begin{array}{l}\text { la } \\
\mathrm{h}_{1}=0.3 \mathrm{~h} \quad \text { but } \leq 0.15 \mathrm{~m} \\
\mathrm{~h}_{2}=0.3 \mathrm{~h} \quad \text { but } \geq 0.10 \mathrm{~m} \\
\text { but } \leq 0.25 \mathrm{~m}\end{array}$}} & \multicolumn{5}{|c|}{ 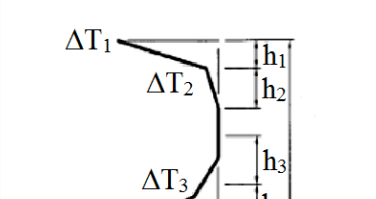 } \\
\hline 3b. Concrete beams & & & & & $\begin{array}{l}\mathrm{h}_{1}=\mathrm{h}_{4} \\
\mathrm{~h}_{2}=\mathrm{h}_{3}\end{array}$ & $\begin{array}{l}=0.2 \\
=0.2\end{array}$ & $\begin{array}{ll}h & \text { bu } \\
h & \text { bu }\end{array}$ & $\begin{array}{l}\text { it } \leq 0 \\
\text { it } \leq 0\end{array}$ & $25 \mathrm{~m}$ \\
\hline$-100 \mathrm{~mm}$ surfacing & $\mathrm{h}$ & $\Delta \mathrm{T}_{1}$ & $\Delta \mathrm{T}_{2}$ & $\Delta \mathrm{T}_{3}$ & $\begin{array}{c}\mathrm{m} \\
\leq 0.2\end{array}$ & -2.0 & $\begin{array}{c}{ }^{\circ} \mathrm{C} \\
-0.5\end{array}$ & -0.5 & -1.5 \\
\hline 3c. Concrete box girder & $\begin{array}{c}\mathrm{m} \\
\leq 0.2 \\
0.4 \\
0.6 \\
\geq 0.8 \\
\end{array}$ & $\begin{array}{c}8.5 \\
12.0 \\
13.0 \\
13.0\end{array}$ & $\begin{array}{l}{ }^{\circ} \mathrm{C} \\
3.5 \\
3.0 \\
3.0 \\
3.0\end{array}$ & $\begin{array}{l}0.5 \\
1.5 \\
2.0 \\
2.5\end{array}$ & $\begin{array}{c}0.4 \\
0.6 \\
0.8 \\
1.0 \\
\geq 1.5 \\
\end{array}$ & $\begin{array}{l}-4.5 \\
-6.5 \\
-7.6 \\
-8.0 \\
-8.4\end{array}$ & $\begin{array}{l}-1.4 \\
-1.8 \\
-1.7 \\
-1.5 \\
-0.5\end{array}$ & $\begin{array}{l}-1.0 \\
-1.5 \\
-1.5 \\
-1.5 \\
-0.5\end{array}$ & $\begin{array}{l}-3.5 \\
-5.0 \\
-6.0 \\
-6.3 \\
-6.5\end{array}$ \\
\hline
\end{tabular}

Fig. 1. Temperature differences for bridge deck, [7] - case 3c)

The uniform temperature component depends on the minimum and maximum temperature which a bridge will reach. This results in changes of uniform temperature which in an unrestrained structure would result in a change in element length. The values of minimum and maximum uniform bridge temperature components $\square \mathrm{TN}$ for restraining forces shall be derived from the minimum $\left(\mathrm{T}_{\min }\right)$ and maximum $\left(\mathrm{T}_{\max }\right)$ shade air temperatures, that can be gain from the isotherms in accordance to the bridge exposition.

Over a time period heating and cooling of a bridge deck upper surface will result in a maximum heating (top surface warmer) and a maximum cooling (bottom surface warmer) temperature variation, $\left(\Delta \mathrm{T}_{\mathrm{M} \text {,heat }}\right.$ and $\left.\Delta \mathrm{T}_{\mathrm{M}, \text { cool }}\right)$. The effect of the vertical temperature differences should be considered by including a non-linear temperature difference component, $\Delta \mathrm{T}_{\mathrm{E}}$. Fig. 1 represents the temperature differences along the cross section on bridge decks. Our case is the case $3 \mathrm{c}$ ). These gradient incorporates parts of $\Delta \mathrm{T}_{\mathrm{M}}$ and $\Delta \mathrm{T}_{\mathrm{E}}$ and the small part of the component $\Delta \mathrm{T}_{\mathrm{N}}$. 


\section{Bridge Geometry and Measuring Equipment Description}

In this period we are monitoring a concrete box girder bridge SO 201-10 which is situated on the highway near the Zilina airport. We had started to observe it June 2015. Bridge has nine spans $(48 \mathrm{~m}+3 \times 58 \mathrm{~m}+60 \mathrm{~m}+2 \times 68 \mathrm{~m}+54 \mathrm{~m}+37.1 \mathrm{~m})$ and it is built by using incremental launching method with $39 \mathrm{~m}$ long steel launching nose, see Fig. 2. The overall span of the bridge is $835.1 \mathrm{~m}$ and with his main span it is crossing the highway and railway. The bridge superstructure is made with a continuous box girder simple supported by the piers and abutments. Hight of the cross-section varies from $3.85 \mathrm{~m}$ to $4.5 \mathrm{~m}$.

Concrete strength class has been designed $\mathrm{C} 45 / 55$ and prestressing tendons with characteristic strength of $1860 \mathrm{MPa}$. The tendons consist of 19 strands (bonded tendons) and 27 strands (free tendons) of diameter $15.7 \mathrm{~mm}$.

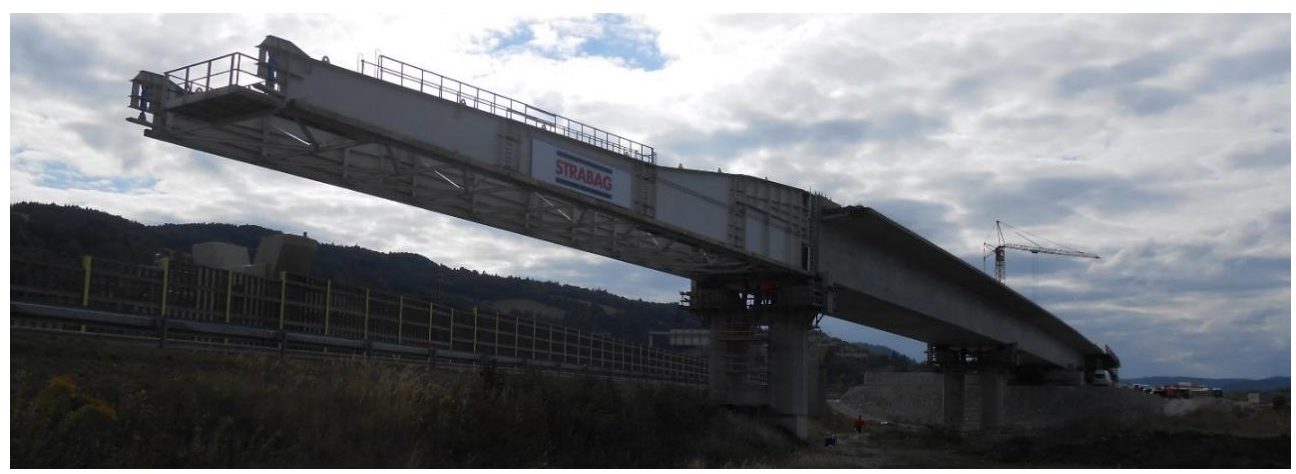

Fig. 2. Bridge 201-10 - construction stage with two spans completed

In the construction stage of the bridge was installed measuring equipment with 19 strain gauges type TES/5.5/T embedded in concrete to measure strain and temperature, 8 thermocouples to measure surface temperature and 2 thermometers for measuring air temperature. These sensors are divided into two measured cross sections of the first span, see Figs. $6 \sim 10$. Measured cross-section (MP1) and measured cross-section (MP2). Cross-section MP1 is placed at 3/5 of the first span and includes strain gauges (S1 S7). Cross-section MP2 is placed very next to the crossbeam and includes strain gauges (S1 S11), thermocouples (TP1 TP7), interior and exterior air thermometers (TE1, TE2) and one thermometer embedded in depth $400 \mathrm{~mm}$ (TC400). All of these sensors have been continually monitored and recorded.

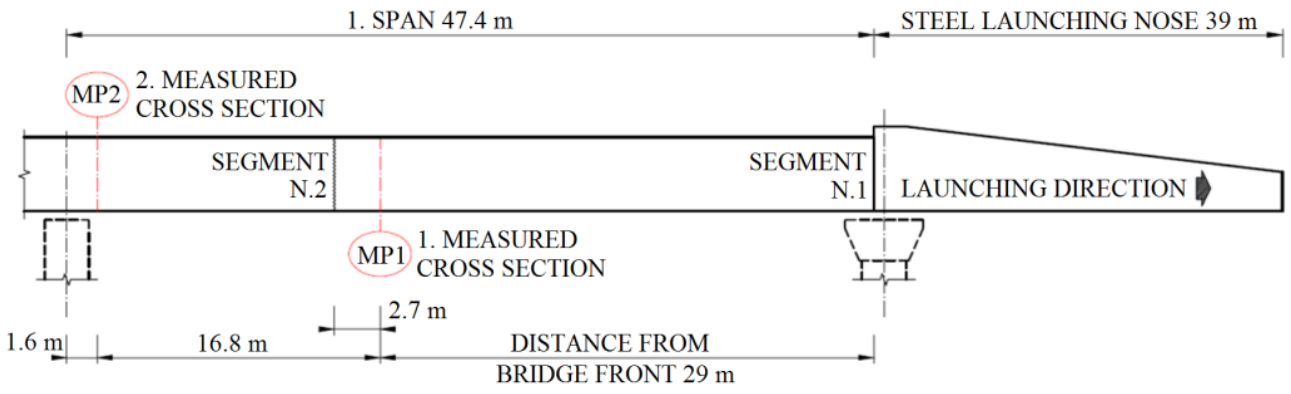

Fig. 3. Placing of measured cross sections in the first span 


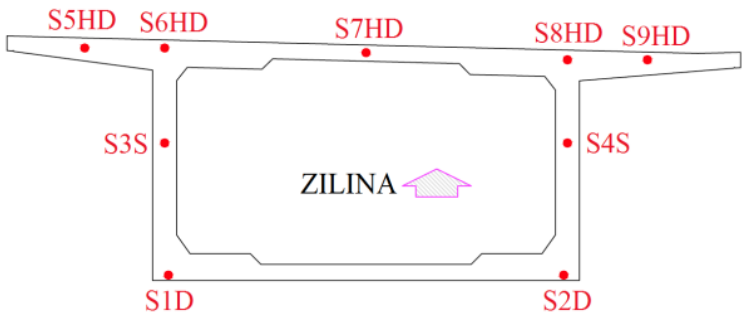

Fig. 4. Strain gauges layout at MP1

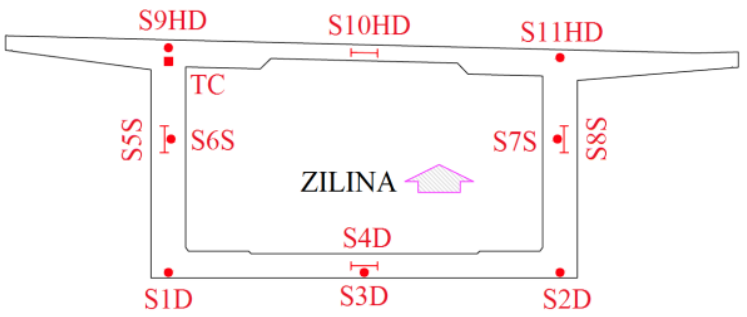

Fig. 5. Strain gauges layout at MP2

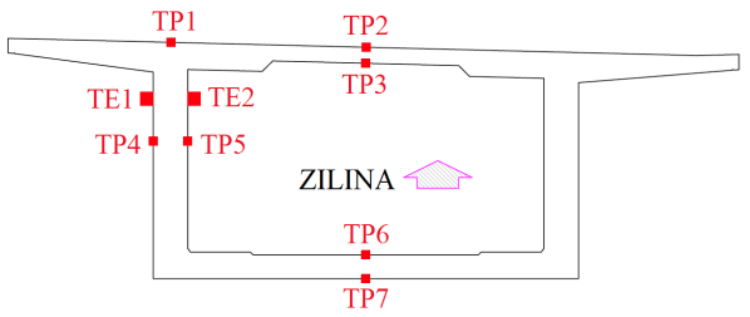

Fig. 6. Thermocouples layout at MP2
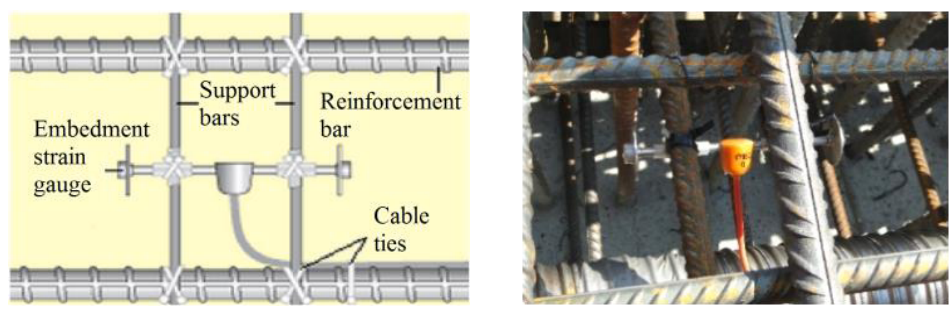

Fig. 7. Strain gauges fixing to the reinforcement bars.

\section{Temperature changes due to temperature of the air}

Last year we described temperature field in concrete box cross section during the summer days with maximum temperature. In this article we will describe measured temperatures during the winter days. Fig. 8 shows diagrams of temperature changes measured during the days from 5th January 2016 to 7th January 2016 for parts of the cross section separately. These diagrams represent period when the temperature of the air reached the minimum value from the date of applying surface thermocouples (TP1 - TP7) to surface of the cross section parts. All the measure temperature have linear trend. The temperature of top slab inner surface (TP3) is lower (up to $3{ }^{\circ} \mathrm{C}$ ) than the temperature inside the box (TE2). Temperatures measured by strain gauge inside the concrete (S10HDt) 
also copies the temperature inside box with the deviation up to $5{ }^{\circ} \mathrm{C}$. Temperature of top slab outer surface is almost identical with the temperature of outside air (TE1).

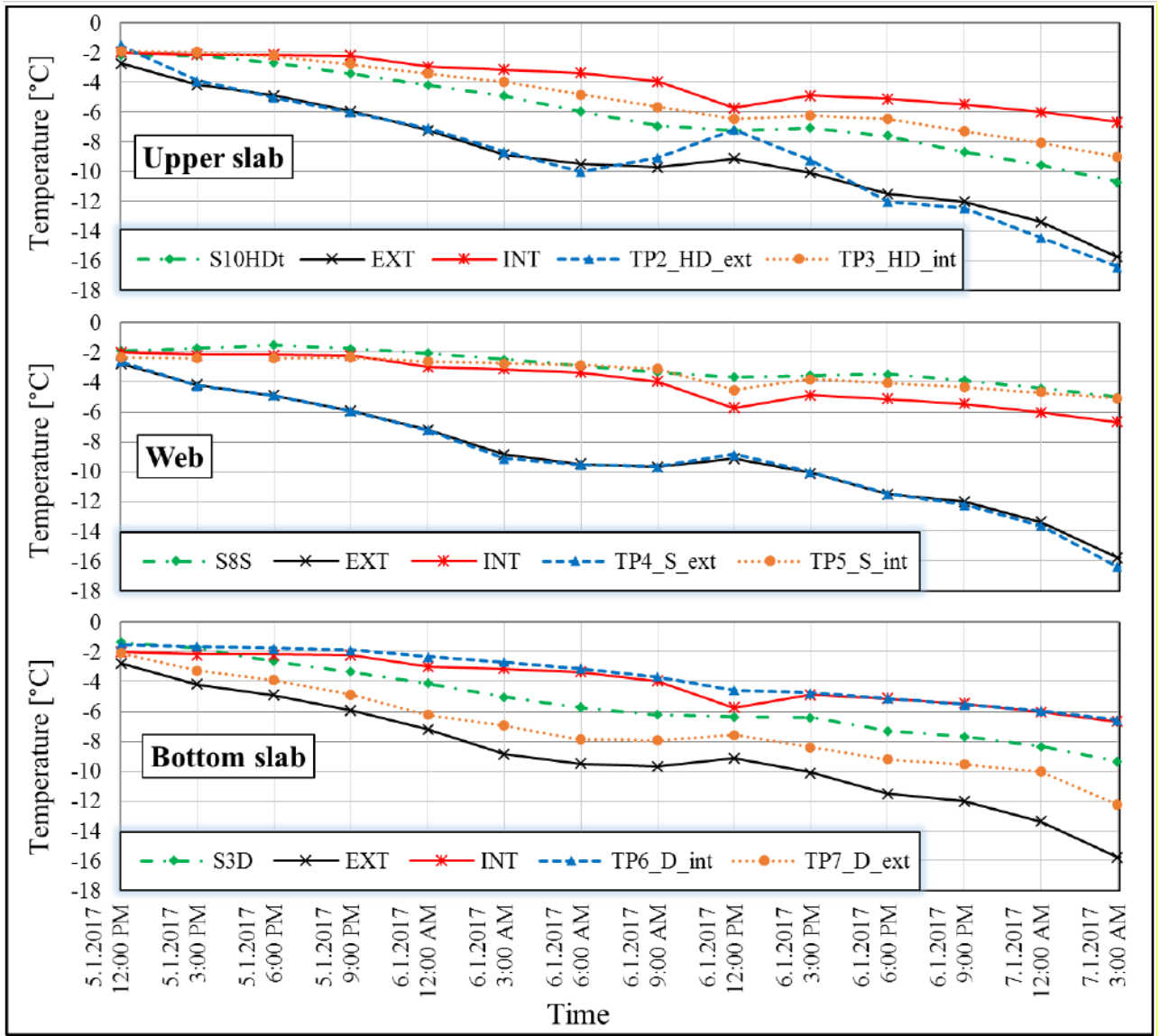

Fig. 8. Temperature variations of concrete over the cross section.

Temperature field of the web is similar to the top slab, but the values measured by strain gauge inside the concrete (S8S) and by surface thermocouple at the inner surface (TP5) are slightly higher than the temperature of the air inside the box (TE2). Outer surface temperature of the web is identical with the temperature of outside air (TE1).

The main difference in temperature field of the bottom slab is, that the temperature of outer surface (TP7) is higher (up to $4{ }^{\circ} \mathrm{C}$ ) than outside air temperature. This leads to development of negative temperature gradient in the cross section. Temperature measured by strain gauge inside the concrete $(\mathrm{S} 3 \mathrm{D})$ is by $2{ }^{\circ} \mathrm{C}$ higher than temperature of outer surface (TP7) and inner surface temperature is identical to the temperature inside the box (TE2).

\section{Temperature gradient}

After the monitoring of temperature changes described in previous paragraphs we tried to create the negative vertical temperature gradient along the cross section of recorded values of temperature in characteristic points. We can create negative vertical temperature gradient by dividing a minimum obtained value of temperature (absolute value) from 
measured temperatures along the cross section. Furthermore we have compared obtained temperature gradient with negative temperature gradient recommended in Slovak annex of the Eurocode STN EN 1991-1-5 for our type of concrete cross section. Comparison presented in Fig. 9 shows that negative temperature gradient obtained from the measurement reach $11.6{ }^{\circ} \mathrm{C}$ and did not exceed the recommended value in Eurocode. It is necessary to say that the temperature of the air at night of 7 th January 2017 did reach value $-23{ }^{\circ} \mathrm{C}$ but we were not able to measure these values because of measuring system power source fail. We can suppose that negative vertical temperature gradient could extend the recommended value in Eurocode.

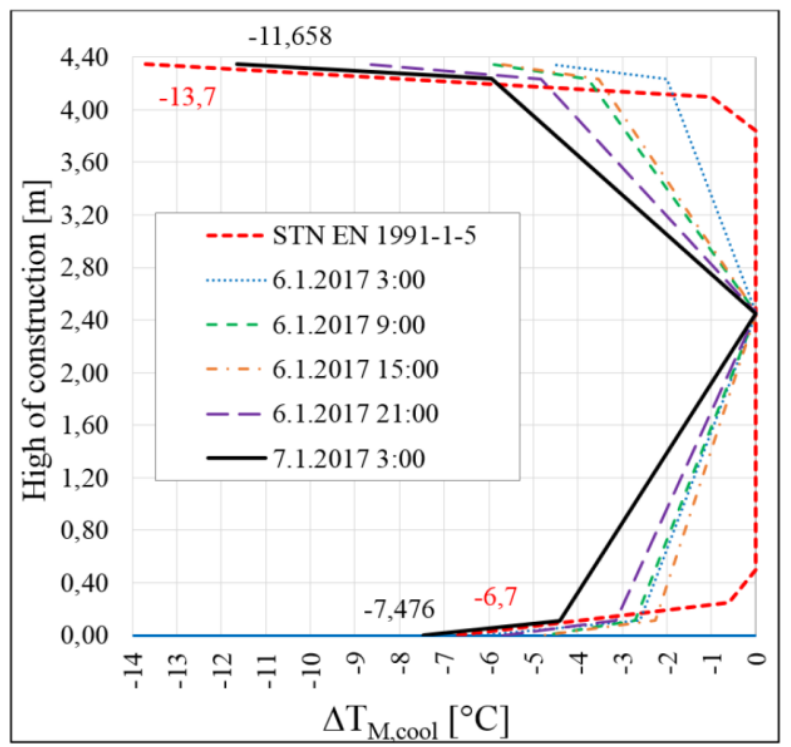

Fig. 9. Comparison of measured temperature gradients with Eurocode recommendation.

\section{Conclusion}

Variations of air temperature affect overall temperature distribution of cross section and large temperature gradient can occur. This temperature gradient, especially vertical temperature gradient can exceed the value in bridge design standard. Underestimation of this problem can affect significantly stresses distribution of the bridge and tensile cracks development. Therefore it is necessary to collect specific temperature gradient data during longer time period continually on various type of bridges. It can allow to do more precise structural analysis of bridge structures in the future.

\section{Acknowledgements}

The research is supported by the Slovak Research and Development Agency under contract No. APVV-0736-12 and by Research Project No. 1/0336/15 and 2/0033/15 of Slovak Grant Agency VEGA. 


\section{References}

1. M. J. N. Priestley: Design of concrete bridges for temperature gradients, American Concrete Insititute Journal, May, pp. 209-217, (1978).

2. J. H. Emanuel, J. L. Hulsey: Temperature distribution in composite bridges, Journal of the Structural Division, ASCE, vol.104.ST1, pp.65-78, (1987).

3. M. M. Elbadry, A. Ghali: Temperature variations in concrete bridges, Journal of the Structural Engineering, ASCE, vol. 109(10), pp.2355-2374, (1983).

4. M. Emerson: Thermal movements of concrete bridges: field measurements and methods of prediction, Transportation Road Research Laboratory Supplementary Report

747 , pp.5-10, (1982).

5. J. Rimal: Comparison of temperature loadings of bridge girders, Czech Technical University in Prague, vol. 48(05), pp.22-8, (2008).

6. Guang-Dong Zhou, Ting-Hua Yi, Thermal Load in Large-Scale Bridges: A State-ofthe-Art Review. International Journal of Distributed Sensor Networks, (2014).

7. STN EN 1991-1-5: Actions on Structures. Part 1-5: General Actions - Thermal actions.

8. STN EN 1990: Eurocode. Basis of structural design.

9. Moravcik, M. - Bahleda, F. - Jost, J. - Dolinajova, K.: Monitoring of Long-Term Effects on Concrete Bridge Realised by Balanced Cantilever Method. Proceedings of the International Conference on Civil, Structural and Transportation Engineering (ICCSTE' 15), http://avestia.com/ICCSTE2015 Proceedings, Ottawa, Ontario, Canada, May 4-5, (2015).

10. CSN 73 6203: Actions on Bridges.

11. BS 5400-2: Steel, Concrete and Composite Bridges. Part 2: Specification for Loads.

12. DIN 1072: Road and Food Bridges: Design Loads.

13. ASSHTO 2012: LRFD Bridge Design Specification. 